УДК 630*181.65:633.877.3(571.54/55)

КОЛЕБАНИЕ ЛИНЕЙНЫХ ПРИРОСТОВ В МОЛОДЫХ КУЛЬТУРАХ СОСНЫ В ЗАБАЙКАЛЬСКОМ КРАЕ

Пак Л.Н.

ФГБУН «Институт природных ресурсов, экологии и криологии СО РАН», Чита, e-mail:pak_lar@bk.ru

Одной из наиболее распространенных древесных пород на территории Забайкальского края является сосна обыкновенная. Потребность восстановления сосновых лесов является одной из приоритетных проблем в последнее время. Анализ существующей практики закладки сосновых искусственных насаждений, говорит о тенденции большого списания лесных культур, созданных на механически обработанных участках на не покрытых лесом землях. Чтобы решить эту проблему, нами проведены исследования по выращиванию лесных культур, созданных на неподготовленной почве. Исследования показали, что в искусственных насаждениях, независимо от варианта, на фоне общего повышения среднего годичного роста в высоту за рассматриваемый период, отмечается период его снижения в отдельные годы (2013-2015 гг.). Величина колебания индивидуального прироста деревьев в вариантах по годам имела максимальные значения в 20132015 гг. Распределение годичного роста в высоту по градациям по годам показало на переход к следующей возрастной группе (с ростом в высоту 1-25 см) в 2014 г. Между метеопараметрами и годичным ростом в высоту, колебанием прироста лесных культур установлена положительная корреляция только с учетом средней температуры воздуха $(\mathrm{r}=0,49)$. Лесные культуры относительно спокойно реагируют на перепады количества выпавших осадков в учетном году. Между годами (пиками) солнечной активности и рассматриваемыми показателями лесных культур, а также количеством выпавших осадков установлена положительная связь $(\mathrm{r}=0,6)$. Учитывая данный факт, лесокультурные работы необходимо проводить в большом объеме в годы солнечной активности независимо от варианта. С экономической точки зрения лесные культуры, созданные на неподготовленной почве, снижают затраты на проведение трудоемких и дорогостоящих работ.

Ключевые слова: Забайкальский край, лесные культуры, сосна, рост, колебания

\title{
FLUCTUATION OF LINEAR GROWTH IN YOUNG CULTURES OF PINE IN ZABAIKALSKY KRAI
}

\author{
Pak L.N.
}

Institute of Natural Resources, Ecology and Cryology of SBRAS, Chita, e-mail: pak_lar@bk.ru

One of the most common tree species at the territory of Zabaikalsky Krai is Scots pine. The need to restore pine forests is one of the priority problems in recent years. Analysis of current practice, bookmark pine artificial plantations, suggests a large decline in forest crops created on mechanically treated plots on non-forested lands. To solve this problem, research on the cultivation of forest crops created on untreated soil were conducted. Studies have shown that in artificial plantations, regardless of the option, against the background of an overall increase in the average annual growth in height for the period under review, there is a period of decline in some years (2013-2015). The magnitude of the fluctuation of individual growth of trees in the variants by year had the maximum values in 2013-2015. The distribution of the annual height increased according to the gradations by year showed a transition to the next age group (with a height increase of 1-25 cm) in 2014. Between the meteorological parameters and the annual growth in height, the fluctuation in the growth of forest cultures established a positive correlation only considering the average air temperature $(r=0.49)$. Forest cultures react relatively calmly to variations in the amount of precipitation in the reference year. Between the years (peaks) of solar activity and the considered indicators of forest crops, as well as the amount of precipitation, a positive relationship was established $(r=0.6)$. Considering this fact, silvicultural works should be carried out in a large volume during the years of solar activity, regardless of the variant. From an economic point of view, forest cultures created on unprepared soil reduce the costs of laborious and expensive work.

Keywords: Zabaikalsky Krai, planted forest, pine, growth, fluctuation

Одной из наиболее распространенных древесных пород на территории Забайкальского края является сосна обыкновенная (Pínus sylvéstris). На ее долю приходится $7,8 \%$ от общей площади лесов и $9,0 \%$ от покрытой лесом площади края (по состоянию на 01.01.2018 г.) [1].

Потребность восстановления сосновых лесов является одной из приоритетных проблем в связи с их интенсивной эксплуатацией, повышением рекреационной нагрузки, многочисленно повторяющимися лесными пожарами, массовым поражением лесны- ми вредителями и болезнями, смены пород, а также климатическими изменениями, направленными на сокращение лесопокрытой площади.

Анализ существующей практики закладки сосновых искусственных насаждений на супесчаных и песчаных почвах Забайкальского края на протяжении последних 10 лет говорит о тенденции большого списания лесных культур, созданных на механически обработанных участках на непокрытых лесом землях. Чтобы решить эту проблему, учитывая ежегодные значи- 
тельные объемы лесокультурных работ, сократить материальные и трудовые затраты, ускорить посадку лесных культур на вырубках и гарях, нами проведены исследования по выращиванию лесных культур, созданных на неподготовленной почве. Тем более что положительный опыт закладки искусственных насаждений данным способом в стране уже был [2-4].

Цель настоящей работы заключалась в изучении величины и колебаний роста в высоту в лесных культурах, созданных на подготовленной и неподготовленной почве, которые являются одними из показателей, характеризующих состояние деревьев и насаждения в целом по вариантам.

\section{Материалы и методы исследования}

Экспериментальный объект (лесные культуры сосны, созданные на неподготовленной почве) расположен в окрестностях Ингодинского лесного стационара ИПРЭК СО РАН в нижнем течении бассейна р. Какова (в 40 км от г. Читы). Согласно лесорастительному районированию эта территория относится к Забайкальскому горному лесному району.

Закладку сосновых насаждений (экспериментальный вариант) проводили в 2010 г., одновременно с производственными посадками (контрольный вариант) на вырубках по гарям 2000 и 2008 гг. Эти участки ранее были заняты сосняком рододендроново-разнотравным III-IV классов бонитета.

Обработку почвы для производственных посадок осуществляли с помощью плуга ПКЛ-70, с нарезкой борозд через 3 м. Посадку 3-летних сеянцев, выращенных в питомнике Сивяковского участкового лесничества (рядом с Ингодинским лесным стационаром ИПРЭК СО РАН), выполняли вручную, под меч Колесова, в дно борозды, с шагом посадки - 0,7 м. Все производственные работы проведены работниками Читинского лесничества.

Экспериментальные посадки выполнены нами на неподготовленной почве (целине) между бороздами в трехкратной повторности (300 штук сеянцев в каждой повторности) на каждом из участков.

Изучение роста деревьев для сравнения и оценки вариантов закладки осуществляли в период 2012-2017 гг., т.е. на 2-7-й год после посадки. Для работы использовали общепринятую методику В.В. Огиевского, А.А. Хирова [5].

Для изучения колебания индивидуальных приростов проведено сравнение приростов по каждому году с приростами предыдущего года каждого дерева. Затем определен процент участия в насаждении деревьев с повышенным в данном году приростом. Таким образом, показатель величины колебания индивидуальных приростов в насаждении характеризовался процентом деревьев с повышенным приростом в изучаемом году по сравнению с предыдущим годом. Если более 50 \% деревьев увеличивало прирост, то колебание индивидуальных приростов считалось положительным, если менее $50 \%$ - отрицательным.

Для детального исследования искусственных насаждений проведено расчленение деревьев по величине колебания индивидуальных ростов в высоту на следующие градации: от 1 до 25, от 26 до 50, от 51 до 75 , от 76 до 100 , от 101 до 125 , от 126 до 150 , от 151 до 175, от 176 до 200 см по сравнению с предыдущим годом.

Изучение динамики колебаний основных метеопараметров (температуры и влажности воздуха) за период 2010-2017 гг. проводили с использованием данных сайта rp5.ru. Рассмотрению подлежали показания за период с апреля по сентябрь по каждому учетному году.

\section{Результаты исследования и их обсуждение}

Результаты проведенного исследования показали, что кульминация среднего годичного роста в высоту в вариантах еще не наступила (табл. 1). За весь рассматриваемый период максимальные значения отмечались в последний учетный год $(52,8$ и 57,0 см экспериментальный вариант и контрольный вариант соответственно).

В варианте лесных культур, созданных на неподготовленной почве, средний годичный рост в высоту по годам менялся следующим образом: после посадки, в первые два года, он был незначительным и практически одинаковым. Затем, в 2012 г. рост в высоту увеличился на 52,5\% и на протяжении двух лет постепенно снижался. В 2015 г. он упал до 11,5\% по сравнению с предыдущим годом, а потом, в последующие учетные годы, вновь повысился на $21,8 \%$ - в 2016 г. и 22,4\% - в 2017 г. (по сравнению с предыдущим годом). Похожая ситуация просматривалась и в лесных культурах, созданных на подготовленной почве. Здесь незначительное повышение прироста отмечалось на второй год после посадки, которое затем существенно возросло в 2012 г. (на 72,6\%) и на протяжении 
двух лет стало снижаться с небольшими колебаниями. В 2015 г. годичный прирост культур резко уменьшился до 5,0\%, а потом начал изменяться в сторону повышения на $19,6 \%$ - в 2016 г. и 21,6\% - в 2017 г., но все же оставался небольшим на фоне общего тренда увеличения роста в высоту.

В год посадки лесных культур, независимо от варианта, колебания индивидуальных приростов были отрицательными (менее $50 \%$ ) (рис. 1). Начиная с 2011 г. значительно возросли колебания в варианте лесных культур, созданных на неподготовленной почве (на 37,1 \%). Экспериментальный вариант превышал контрольный - на 18,2\%.

За рассматриваемый период, в варианте лесных культур, созданных на неподготовленной почве, колебания индивидуальных приростов были максимальными в 2013 г. $(71,7 \%)$, после чего отмечалось постепенное снижение показателя и к 2017 г. оно уменьшилось на 9,4\%. В контрольном варианте лесных культур максимальное значение приходилось на 2014 г. (66,9\%). Колебания индивидуальных приростов за весь рассматриваемый период не превышали $70 \%$, располагались в пределах 62,1-66,9\%. С 2014 г. колебания снизились на 3,5\%.

Распределение индивидуального прироста по градациям по годам показало на переход ко второй группе с ростом в высоту 26-50 см в 2014 г. в экспериментальном варианте (рис. 2).
Здесь преобладание прироста данной группы сохранилось до 2017 г. В контрольном варианте переход ко второй группе в 2014 г. продолжался всего лишь один год, с 2015 г. по настоящее время снова наметилась тенденция снижения, перехода к первой группе деревьев с ростом в высоту 1-25 см.

Статистическая обработка метеопараметров показала, что в течение рассматриваемых лет данные не оставались постоянными, наблюдалась их незначительная изменчивость. Так, в первые два года после посадки средняя температура воздуха имела небольшую изменчивость в сторону повышения, а с 2012 г. начала постепенно снижаться (на 6,0\% по сравнению с предыдущим годом). В 2013 г. эта тенденция продолжилась еще на 3,6\%, поэтому год был прохладным. С 2014 г. средняя температура воздуха возросла на $11 \%$ и в последующие два года незначительно колебалась, в пределах от $0,9 \%$ до -4,7\%. В 2017 г. она вновь возросла на 6,1\%. Изменчивость количества выпавших осадков по годам была более значительной. Так, начиная с 2010 по 2012 гг. шло постепенное увеличение количества осадков. С 2013 г. отмечается существенное снижение (на 79,3\%) данного показателя, которое продолжилось в следующем учетном году еще на 38,6\%. Небольшое повышение количества осадков в 2015 и 2016 гг. вновь сменилось снижением данного показателя на 7,4\%.

Статистические данные среднего годичного роста в высоту за период с 2010 по 2017 г.

\begin{tabular}{|c|c|c|c|c|c|}
\hline Год & $\begin{array}{c}\text { Средний прирост } \\
\text { ошибка средней } \\
(M+m)\end{array}$ & $\begin{array}{c}\text { Среднее квадратиче- } \\
\text { ское отклонение } \\
( \pm \sigma)\end{array}$ & $\begin{array}{c}\text { Коэффициент } \\
\text { вариации }(V)\end{array}$ & $\begin{array}{c}\text { Показатель } \\
\text { точности } \\
(p), \%\end{array}$ & $\begin{array}{c}\text { Критерий досто- } \\
\text { верности разницы } \\
\text { прироста }(t)\end{array}$ \\
\hline \multicolumn{5}{|c|}{ Экспериментальный вариант } \\
\hline 2010 & $11,56 \pm 0,57$ & 6,1 & 53,1 & 4,9 & 0,8 \\
\hline 2011 & $11,35 \pm 0,59$ & 7,3 & 64,3 & 5,1 & 1,1 \\
\hline 2012 & $17,32 \pm 0,82$ & 10,34 & 59,6 & 4,7 & 5,8 \\
\hline 2013 & $23,7 \pm 1,10$ & 14,37 & 60,6 & 4,6 & 1,3 \\
\hline 2014 & $31,76 \pm 1,44$ & 18,48 & 59,1 & 4,5 & 0,1 \\
\hline 2015 & $35,43 \pm 1,81$ & 22,34 & 63,0 & 5,1 & 0,1 \\
\hline 2016 & $43,17 \pm 2,25$ & 27,40 & 63,4 & 5,2 & 0,1 \\
\hline 2017 & $52,86 \pm 2,73$ & 33,20 & 62,8 & 5,1 & \\
\hline \multicolumn{7}{|c|}{ Контрольный вариант } & & \\
\hline 2010 & $8,34 \pm 0,61$ & 5,63 & 67,5 & 7,3 & 0,1 \\
\hline 2011 & $9,53 \pm 0,67$ & 7,86 & 82,4 & 8,0 & 9,3 \\
\hline 2012 & $16,45 \pm 1,06$ & 12,90 & 78,4 & 6,4 & \\
\hline 2013 & $24,47 \pm 1,85$ & 17,20 & 70,2 & 5,8 & 6,8 \\
\hline 2014 & $37,30 \pm 2,08$ & 25,60 & 68,6 & 5,5 & 0,5 \\
\hline 2015 & $39,20 \pm 2,30$ & 28,70 & 73,2 & 5,8 & \\
\hline 2016 & $46,90 \pm 3,0$ & 36,60 & 78,0 & 6,3 & 0,1 \\
\hline 2017 & $57,05 \pm 3,63$ & 44,40 & 77,8 & 6,3 & \\
\hline
\end{tabular}




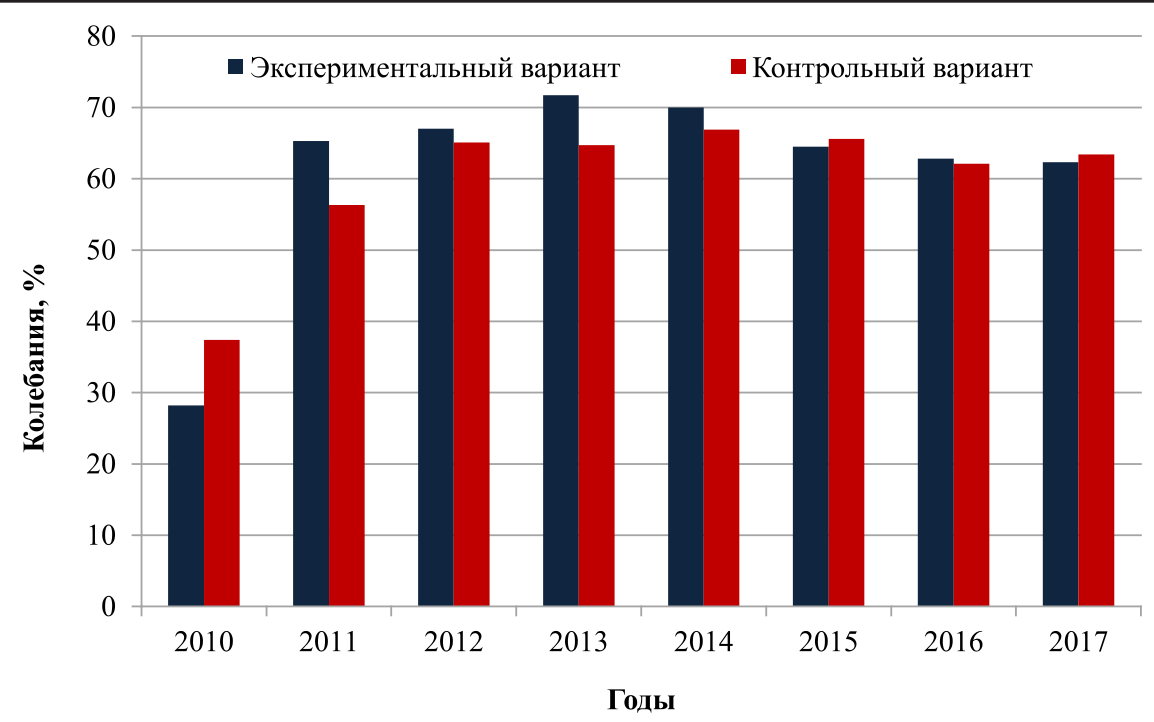

Рис. 1. Колебания приростов по вариантам за период с 2010 по 2017 г2., \%

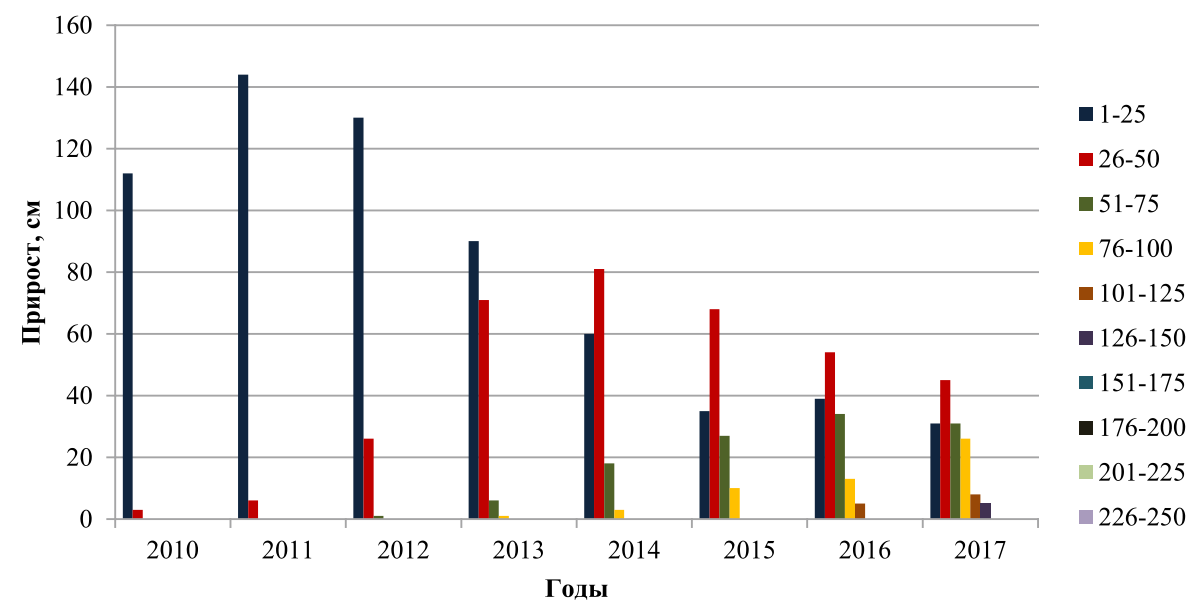

a)

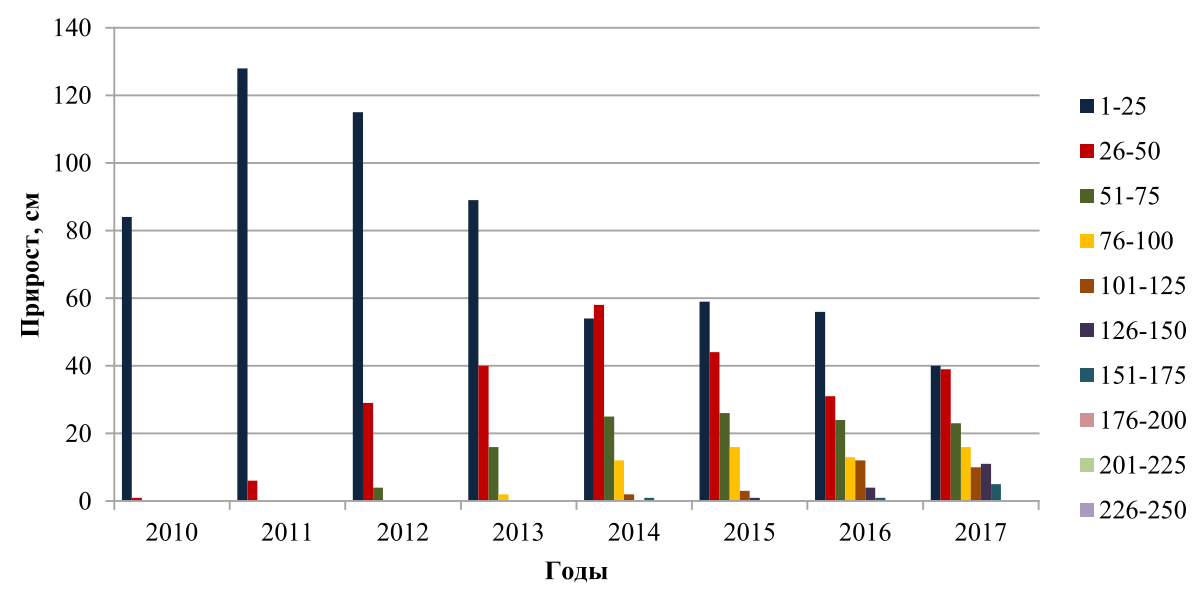

б)

Рис. 2. Распределение деревьев по индивидуальным линейным приростам по годам и вариантам: а) экспериментальный вариант; б) контрольный вариант) 
Выявление зависимости между метеопараметрами и годичным ростом в высоту, колебанием прироста лесных культур показало, что положительная корреляция прослеживается в обоих вариантах, только с учетом средней температуры воздуха $(\mathrm{r}=0,49)$. Связь между всеми рассматриваемыеми показателями лесных культур и количеством выпавших осадков установить не удалось. Очевидно, что лесные культуры относительно спокойно реагируют на перепады количества выпавших осадков в учетном году.

Интересно отметить тот факт, что существенное снижение годичного прироста в вариантах (по сравнению с предыдущими годами после посадки) отмечается в период 2013-2015 гг., когда в вариантах происходят наибольшие колебания повышенного прироста и когда идет переход к следующей группе прироста с ростом в высоту 26-50 см.

Изучение зависимости между солнечной активностью и рассматриваемыми показателями лесных культур, а также метеопараметрами показало на наличие положительной корреляции между годами солнечной активности и колебаниями прироста (в диапазоне $\mathrm{r}=0,5-0,6)$ и между годами солнечной активность и количеством выпавших осадков $(\mathrm{r}=0,2)$.

\section{Выводы}

Исходя из вышеизложенного, можно сделать следующие выводы:

1. В искусственных насаждениях, независимо от варианта, на фоне общего повышения среднего годичного роста в высоту за рассматриваемый период, отмечается период его снижения в отдельные годы (2013-2015 гг.).

2. Величина колебания индивидуального прироста деревьев в вариантах по годам имела максимальные значения в 2013-2015 гг.

3. Распределение годичного роста в высоту по градациям по годам показало на переход к следующей возрастной группе (с ростом в высоту 1-25 см) в 2014 г.

4. Между метеопараметрами и годичным ростом в высоту, колебанием прироста лесных культур установлена положительная корреляция только с учетом средней темпе- ратуры воздуха $(\mathrm{r}=0,49)$. Лесные культуры относительно спокойно реагируют на перепады количества выпавших осадков в учетном году.

5. Между годами (пиками) солнечной активности и рассматриваемыми показателями лесных культур, а также количеством выпавших осадков установлена значимая связь $(\mathrm{r}=0,6)$. Учитывая данный факт, лесокультурные работы необходимо проводить в большом объеме в пики солнечной активности независимо от варианта. В нашем случае - это 2013-2015 годы. С экономической точки зрения лесные культуры, созданные на неподготовленной почве, выгодно создавать, так как они снижают затраты на проведение трудоемких и дорогостоящих работ.

\section{Список литературы / References}

1. Доклад об экологической ситуации в Забайкальском крае за 2017 год. Чита: ГБУ «Забайкальский краевой экологический центр», 2018. 240 с.

The report on an ecological situation in Zabaykalsky Krai for 2017. Chita: GBU «Zabajkal'skij kraevoj ehkologicheskij centr», 2018. 240 p. (in Russian).

2. Гаврилова О.И., Пак К.А., Морозова И.В., Юрьева А.Л. Формирование искусственных сосновых древостоев в условиях карельской таежной зоны // Известия высших учебных заведений. Лесной журнал. 2017. № 4. С. 23-33. DOI: 10.17238/issn0536-1036.2017.4.23.

Gavrilova O.I., Pak K.A., Morozova I.V., Yuryeva A.L. Formation of Artificial Pine Stands in the Karelian Taiga Zone // Bulletin of higher educational institutions. Lesnoy zhurnal (Forestry Journal). 2017. № 4. P. 23-33 (in Russian).

3. Морозова И.В., Гаврилова О.И. Закономерности роста культур сосны в течение первых пяти лет после посева семян и посадки сеянцев на вырубках Южной Карелии // Ученые записки Петрозаводского государственного университета. 2011. № 2 (115). C. 49-51.

Morozova I.V., Gavrilova O.I. Regularities of growth of cultures of a pine within the first five years after crops of seeds and landing of seedlings on cuttings of the Southern Karelia // Uchenye zapiski Petrozavodskogo gosudarstvennogo universiteta. 2011. № 2 (115). P. 49-51 (in Russian).

4. Хлюстов В.К., Гаврилова О.И., Морозова И.В. Рост культур сосны в конкурентных отношениях с живым напочвенным покровом вырубок // Известия Тимирязевской сельскохозяйственной академии. 2010. Вып. 2. С. 27-34.

Hlyustov V.K., Gavrilova O.I., Morozova I.V. Growth of cultures of a pine in a competitive relationship with the living ground cover of the felling // Izvestiya Timiryazevskoj sel'skohozyajstvennoj akademii. 2010. Vyp. 2. P. 27-34 (in Russian).

5. Огиевский В.В., Хиров А.А. Обследование и исследование лесных культур. Ленинград: Типография № 6 Управления печати Ленгорисполкома, 1967. 50 с.

Ogievskij V.V., Hirov A.A. Examination and study of forest crops. Leningrad: Tipografiya № 6 Upravleniya pechati Lengorispolkoma, 1967. 50 p. (in Russian). 